\title{
Study on the Knowledge Gap in Training Organized for Traditional Birth Attendants (TBAs) in Rural Guatemala and the Way for Improvement
}

\author{
Sukhjeet Kamboj ${ }^{1}$, Mabel C. Ezeonwu ${ }^{2}$, Jennifer Hoock ${ }^{3}$ and \\ Suryabir Kamboj ${ }^{4}$ \\ ${ }^{1}$ Wellspan Good Samaritan Family Medicine Residency program Lebanon, Pennsylvania, USA \\ ${ }^{2}$ University of Washington, Seattle, Washington, USA \\ ${ }^{3}$ Faculty Family Physician Kaiser Permanente, Seattle, Washington, USA and Founder \\ of Guatemala Village Health \\ ${ }^{4}$ University of Western Ontario, Canada
}

\begin{abstract}
Objectives: This study aimed to identify knowledge gaps in the clinical skills of traditional birth attendants TBAs to address them and subsequently help to improve the outcomes of home deliveries in rural Guatemala. An implementation of a basic training program addressed the knowledge gaps.

Design and Method: A qualitative study consisting of interviews with 6 practicing traditional birth attendants (TBAs) utilizing qualitative analysis followed by a training session for prenatal care Setting: Q'echi-Mayan speaking communities in a lake. Izabel and hills regions of Guatemala

Findings: Significant deficits in knowledge of the TBAs regarding the physiology of pregnancy and skills for management of common high-risk conditions, such as hyperemesis and pregnancy-induced hypertension, that require referral to other skilled birth attendants (SBAs) and to manage these situations early to prevent complications. This study helped to identify barriers faced by traditional birth attendants in the remote Mayan communities. A program that employed a teaching tool based on WHO recommendations were employed to teach TBAs, which was well accepted by TBAs.

Results/Conclusions: Traditional birth attendants reported significant knowledge gaps. The study emphasizes the importance of supplementing the training of TBAs with additional periodic training and refreshers.
\end{abstract}

Keywords: Traditional birth attendants, home births, comadrona, training, Guatemala, skills, assessment

\section{Introduction}

TBAs are essential to both the local community and national health infrastructure as their training and integration in the current healthcare system can improve maternal and neonatal outcomes in low and medium-income countries (LMICs). There is the immense importance of recognizing and referring high-risk pregnancies as these are factors that inarguably improve maternal health outcomes ( Byrne \& Morgan 2011). Recently, there have been national efforts in Guatemala to help integrate traditional birth attendants TBAs known as comadronas into the healthcare system by providing licenses to comadronas that attend monthly national training. During these meetings, national health staff teaches them about signs and symptoms of danger that require referral during pregnancy (Chary et al., 2013). The national monthly training program has no way of assessing whether comadronas are gaining knowledge and applying it. This study aimed to identify knowledge gaps in the clinical skills of TBAs in order to address them and subsequently improve the outcomes of home deliveries in rural Guatemala. A session of the basic training program was included to initiate addressing the knowledge gap. 


\section{Background and Rationale}

Developing countries have very high perinatal and maternal mortality rates, with more than 358000 mothers (World Health Organization. Trends in maternal mortality: 1990 to 2008 estimates developed by WHO, UNICEF, UNFPA, and The World Bank. 2010.World Health Organization, 2010) and six million babies dying annually (World Health Organization. Millennium development goals report: 2007 United Nations Department of Economical and Social Affairs. United Nations, 2007). The maternal mortality rate (MMR) in the developing world, within rural and indigenous populations, continues to be unacceptably high (Zureick-Brown et al., 2013; Alkema et al., 2016). The millennium development goals were to encourage improvement in social and economic conditions in the world's poorest countries by 2015. There is a significant disparity in achieving progress towards achieving goal 4 (reducing child mortality) and goal 5 (improving maternal health). The disparities in maternal mortality hold in Guatemala, the national MMR of 88 per 100,000 does not reflect health disparities for indigenous women with MMR of 168 per 100,000. The maternal mortality is almost twice that of their non-indigenous counterparts. Approximately $70 \%$ of indigenous women living in rural Guatemala continue to deliver at home without receiving adequate prenatal care (Ministerio de Salud Publica y Asistencia Social. Encuesta Nacional de SaludMaterno Infantil: Informe Interno Priliminario; Ministerio de Salud Publica y Asistencia Social: Guatemala City, Guatemala, 2017).

The preference for home care during pregnancy and delivery among indigenous women is due to limited access to both medical and essential obstetric care and a cultural preference for TBAs, also known as "Comadronas" (Walsh 2006). An estimated 46 percent of Guatemalan women ages 15 to 64 live in rural communities, and 80 percent of them deliver in their homes with a TBA, also known as comadronas in attendance (MSPAS. Estudio Nacional de Mortalidad Materna 2011. Guatemala City. 2011. Available online:

http://www.mspas.gob.gt/index.php/component/jdownloads/send/94-muerte-materna/805estudio-nacional-demortalidad-materna-2011).

At present, about 60 million births in developing countries occur outside healthcare facilities. An estimated 52 million births occur without skilled birth attendants (SBA) (Darmstadt et al., 2009). The integration of adequately trained TBAs with formal health systems can improve skilled birth attendance. The most significant impact occurred when TBA integration with complementary actions to overcome context-specific barriers to contact SBAs, TBAs, and women (Byrne \& Morgan 2011; Wilson et al., 2011). According to the WHO (WHO 1992), a trained TBA is any TBA who has received a short course of training through the modern health sector to upgrade skills.

The integration of TBAs in mainstream health systems often represent a more feasible, culturally acceptable, and accessible option for women in developing countries. Women often give birth outside of health facilities with the help of a traditional birth attendant (TBAs) who, if trained appropriately, can significantly improve the coverage of maternal and neonatal care, and they can be a component of the strategies to improve perinatal outcomes. Trained TBAs were more knowledgeable on danger signs during pregnancy and childbirth. They were more likely to refer women with complications to a health facility than untrained TBAs in resource-constrained countries, especially in remote rural areas. TBAs should be trained on early identification of mothers with obstetrical complications and prompt referral to health facilities that can provide emergency obstetric care (Hussein \& Mpembeni 2005). The inclusion of community-based experienced TBAs can be considered an essential step in providing culturally sensitive, skilled prenatal care. Thus the competency of TBAs in identifying prenatal and intrapartum complications that require referrals to SBAs and/or transfers to health care facilities becomes a crucial component of the training.

The designed training has to be culturally sensitive in the native language to improve TBAs' knowledge of obstetrical emergencies (Garcia et al., 2018). Although fallen out of favor since the late 1990s, the training programs for TBAs were promoted by WHO to enhance their knowledge in different regions of the world as an 
indispensable public health strategy to reduce the preventable loss of maternal and neonatal lives. TBA training's broad goals were to reduce maternal and child morbidity and mortality and improve women's reproductive health. Objectives included enhancing linkages between modern healthcare services and the community, increasing the number of SBA-attended births, and improving TBA skills and stature. Training programs differed considerably in different areas in how they address these objectives (Fortney 1997).

There are not many qualitative studies available about knowledge gaps of TBAs, although some studies tried to measure the effects of training on clinical skills and access to prenatal care (Wilson et al., 2011). Some other studies have evaluated antenatal care skills by focusing on simulated sessions (Carlough \& McCall 2005) or crosssectional reviews on prenatal skill sets utilizing surveys (Ayiasi et al., 2014). Such studies do not provide a realtime look at how a training program directly affects their trainees' clinical skills to conduct prenatal care.

In Guatemala, training with Guatemala Ministry of Health and Public Welfare (MSPAS) exists, but these training sessions are brief. Supplemental Training programs for comadronas, which are an additional effort to MSPAS training have been used to successfully train TBAs in different regions of Guatemala in partnership with MSPAS and nonprofit organizations (Hernandez et al.,2017).

Guatemala Village Health [GVH], a Seattle-based nonprofit organization, provides healthcare to remote mountain and river villages around Lake Izabal in the Eastern Caribbean Coast. These villages covered by GVH have traditionally received MSPAS training of their TBAs. The regional branch of the MSPAS helps integrate education initiatives for health providers into the current healthcare infrastructure. There have been efforts to include TBAs in the Guatemala Ministry of Health and Public Welfare (MSPAS) to help integrate comadronas into the healthcare system by providing licenses to comadronas that attend monthly national training (Chary et al., 2013).

\section{Objectives}

The purpose of this study was to assess skill gaps of TBAs about pregnancy and early identification of emergencies.

This study also attempted to address the knowledge gap by providing a short training in a culturally sensitive way to improve knowledge of antenatal care and subsequently help to improve the outcomes of pregnancy outcomes in rural region of Guatemala.

\section{Methods}

The study was mainly qualitative. Focus group discussions were conducted in the first half of the day, followed by a break of an hour and a half-day of teaching skills in a group setting.

In-depth discussions were done with six female traditional birth attendants (TBAs/comadronas) from the areas served by GVH in Lake Izabel and mountain regions of Guatemala. Discussions were conducted and digitally recorded in a non-formal group setting by a trained native speaker fluent in Spanish and Q'echi. The discussions were recorded in real-time and translated. Translated transcripts were generated and coded. Conventional content analysis was conducted to generate the themes.

The information about years of experience of these TBAs is provided in table 1. 
Table 1: Years of Experience

\begin{tabular}{|l|l|}
\hline Comadrona & $\begin{array}{l}\text { Experience in } \\
\text { years }\end{array}$ \\
\hline 1 & 15 \\
\hline 2 & 6 \\
\hline 3 & 6 \\
\hline 4 & 15 \\
\hline 5 & 9 \\
\hline 6 & 30 \\
\hline
\end{tabular}

A team of physicians designed the pictorial tool Image 1a and Image 1b, including physicians and professionals, proficient in Spanish from GVH utilizing the World Health Organization (WHO) recommendations. The first session was mainly aiming at primary care needed during prenatal visits.

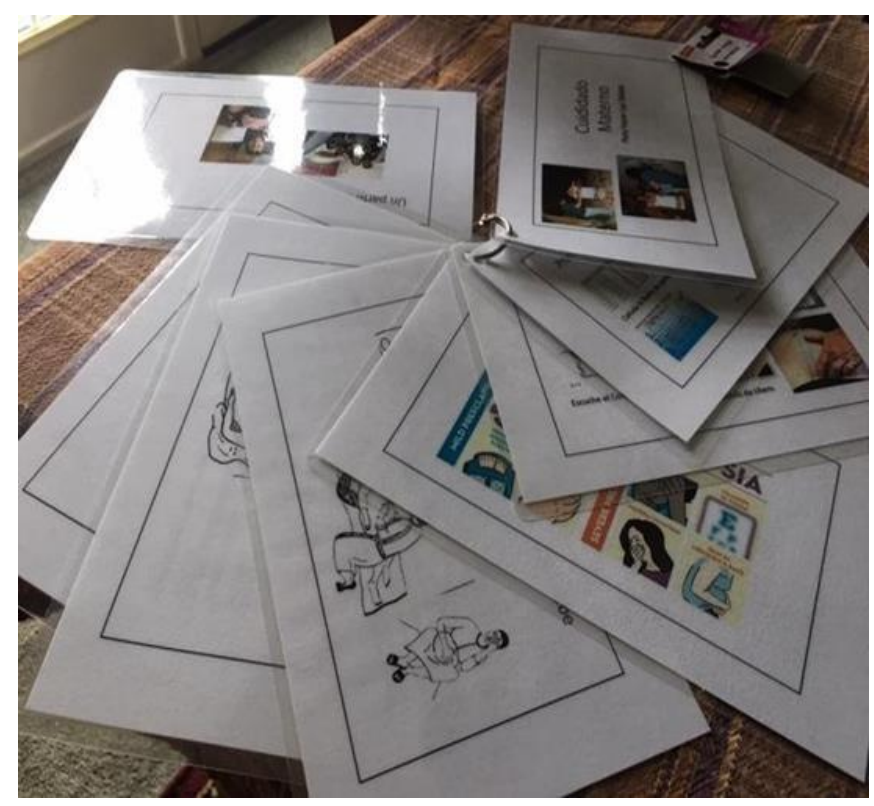

Image 1a: Teaching tool in Spanish 


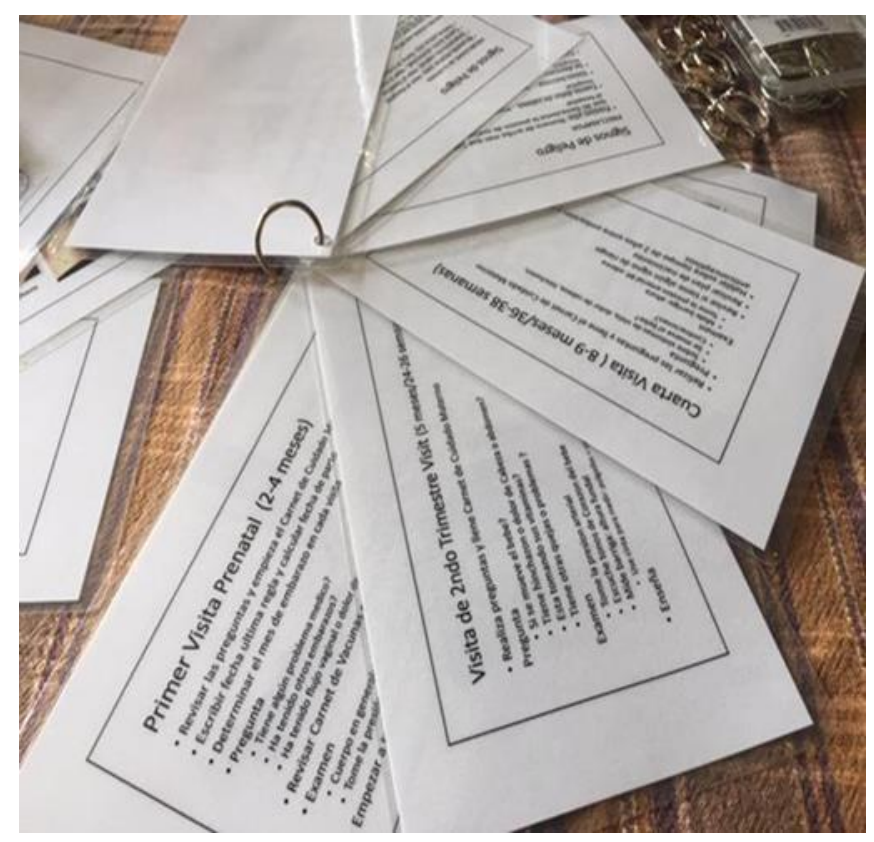

Image 1b: Teaching tool in Spanish

This was used to teach during the second half of the day. The tool was developed in Spanish and Mayan interpreters were utilized to teach the group of Comadronas who spoke Q'echi, a Mayan native language. Antenatal skills and knowledge training was provided in a group teaching format and was directed by a physician. Q'echi speaking interpreter was available to help the Q'echi speaking TBAs.

\section{Outcome/Results}

Key findings from the focus group discussions for knowledge gap analysis, as tabulated in Table 2, indicate that the comadronas possess skills that have helped them provide care to women. Vital community resources for the comadronas in the rural villages were identified, including health promoters who are certified health professionals from MSPAS who often checked blood pressures for their patients when asked for. Also, the obstetrical nurse was a resource for blood work and dispensing of medications. They found themselves supported by health promoters and obstetrical nurses. They have significant knowledge and skill deficits related to some physiologic changes in pregnancy and why they occur. For example, one participant stated that "women have nausea and vomiting during pregnancy because they lack vitamins," Another stated that "high blood pressure is only from fat people." The gaps in knowledge and skills presented in Table 2 provided the discussion points and covered topics in teaching tools for the teaching session. The teaching topics and contents are outlined in Table 3 . The Comadronas/traditional birth attendants felt that they had some patients trying to convince them to go to CIAMIs.

Table 2: Assessment of Needs/Skills Gap among Comadronas

\begin{tabular}{|l|l|l|l|}
\hline $\begin{array}{l}\text { Comadrona } \\
\text { s/TBA }\end{array}$ & $\begin{array}{l}\text { Years in } \\
\text { Practice }\end{array}$ & $\begin{array}{l}\text { Knowledge and Skills } \\
\text { Possessed }\end{array}$ & $\begin{array}{l}\text { Knowledge Deficits and Practice } \\
\text { Challenges }\end{array}$ \\
\hline 1 & 15 & $\begin{array}{l}\text { 1. Ability to evaluate } \\
\text { pregnancy and postpartum } \\
\text { risks and determine when to } \\
\text { refer patients to the health } \\
\text { center } \\
\text { 2. Able to do a cervical } \\
\text { exam after five months }\end{array}$ & $\begin{array}{l}\text { 1. Lacks knowledge of physiologic changes } \\
\text { in pregnancy } \\
\text { 2. Understands that some women are poor } \\
\text { and cannot go to CIAMI due to lack of } \\
\text { transportation/resources } \\
\text { 3. does not know how to assist patients } \\
\text { when referrals are needed to CIAMI. }\end{array}$ \\
\hline 2 & 6 & 1. Ability to evaluate & 1. Lacks Blood pressure measurement and \\
\hline
\end{tabular}




\begin{tabular}{|l|l|l|l|}
\hline & & $\begin{array}{l}\text { pregnancy and postpartum } \\
\text { risks and determine when to } \\
\text { refer patients to the health } \\
\text { center }\end{array}$ & $\begin{array}{l}\text { monitoring skills } \\
\text { 2. Has difficulty convincing women to } \\
\text { accept the referral and seek professional } \\
\text { care when needed }\end{array}$ \\
\hline 3 & 6 & $\begin{array}{l}\text { 1. Ability to evaluate } \\
\text { pregnancy and postpartum } \\
\text { risks and determine when to } \\
\text { refer patients to the health } \\
\text { center }\end{array}$ & None reported \\
\hline 4 & 15 & None reported & $\begin{array}{l}\text { 1. Uncertain about the health of the baby in } \\
\text { utero }\end{array}$ \\
\hline 5 & 9 & $\begin{array}{l}\text { 1. Understands the importance } \\
\text { of child spacing }\end{array}$ & $\begin{array}{l}\text { 1. Not knowing what to do with women } \\
\text { during the first two months of } \\
\text { pregnancy visits }\end{array}$ \\
\hline 6 & 30 & $\begin{array}{l}\text { 2. Ability to measure and } \\
\text { monitor BP }\end{array}$ & $\begin{array}{l}\text { 1. Lacks knowledge of physiologic changes } \\
\text { in pregnancy such as nausea and vomiting } \\
\text { 2. Not knowing how to determine } \\
\text { pregnancy duration and gestational age } \\
\text { 3. Lack of understanding of pregnancy risk } \\
\text { including high BP and preeclampsia and } \\
\text { eclampsia }\end{array}$ \\
\hline
\end{tabular}

Table 3: Training and Education Topics for Comadronas

\begin{tabular}{|l|l|}
\hline Sequence & Topics and Contents \\
\hline 1 & Antenatal care cards. \\
\hline 2 & $\begin{array}{l}\text { Regular physiological changes of pregnancy discussed with the group why nausea and other symptoms } \\
\text { occur in pregnancy. }\end{array}$ \\
\hline 3 & $\begin{array}{l}\text { Importance of getting HCT from health promoters and vitamins when the women come for first prenatal } \\
\text { visits or before pregnancy. }\end{array}$ \\
\hline 4 & Reviewed 2-4 months of visits. \\
\hline 5 & $4-5$ months - they need to go to the health center for checks. \\
\hline 6 & $\begin{array}{l}\text { Fundal height measurement. Tape measures were given, and techniques explained with the return- } \\
\text { demonstration. Explained 1cm = 1 week. Explained how they measure Fundal height from pubis } \\
\text { symphysis. }\end{array}$ \\
\hline 7 & $7-8$ months explained. \\
\hline 8 & $8-9$ months visit explained. \\
\hline 9 & Warning signs explained, especially in the context of preeclampsia, preterm labor, and abruption. \\
\hline 10 & $\begin{array}{l}\text { Fetoscopes were given and used as explained and demonstrated. Notebooks were also given for record- } \\
\text { keeping. }\end{array}$ \\
\hline
\end{tabular}

\section{Conclusions}

The themes identified included a lack of training and knowledge deficits. Most of the TBAs understood the responsibilities of their role. However, they were limited in resources to transfer patients, mainly if patients had financial barriers to go to health centers (CIAMI) if they needed a higher level of care.

The study analysis at baseline and long-term follow-up is required further to analyze the effectivity of training at periodic intervals. Limitations of the study included analyzing the only small area of rural Guatemala, and the challenges may differ in other regions. The research group collaborated with local physicians and health professionals, but there could be cultural and language barriers despite utilizing interpreters and translators. This study is limited in that the viewpoint and/or opinions of the CIAMI workers, MSPAS workers, 
health promotors and obstetrical nurses are not presented. In future research, it would be valuable to discuss, through focus groups and surveys, the opinions of every category of health professionals involved in caring for pregnant patients. These opinions would present a complete picture of the prenatal care available to indigenous women in these areas.

The study's scope was also limited to a knowledge gap analysis of TBAs in prenatal care only, and effective management of the third stage of labor was not included in the study, which is another major contributing factor in poor pregnancy outcomes.

\section{Discussion and Future Directions}

Further ongoing research and periodic training modules and review are required for analysis and closure of the gaps in knowledge of prenatal care. The training modules will need to be modified based on knowledge gaps. The additional knowledge gap analysis should be added to the management of labor.

Multiple previous studies have identified that successful programs in different developing countries are the ones that can be integrated into an existing healthcare system, continue skill development regularly of its participants for at least one year and provide access to birth kits and resuscitation equipment (Jokhio et al., 2005; Byrne \& Morgan 2011; Gill et al., 2011; Wilson et al., 2011).

It will be imperative for comadronas to individually frequently (monthly) review the skills and attend periodic training every six months, which coincides with the biannual GVH organization visits to these areas. The critical step will be to promote a culture of asking help at the time of training and managing the patients in antenatal periods. The health promoters who are proficient in measuring blood pressure and obstetrical nurses trained to measure the fundal height can have periodic visits with these women to continue to review skills with them.

Long term data is needed to track potential improvement in the reported knowledge and skill level of the comadronas. This will be an ongoing project for future visits to these villages. Integrating locally experienced and trained comadronas to teach and assess peers in these programs will have cultural acceptance from the communities.

Once the initial gap is addressed, there is a need to continue assessing the skills regularly. There are culturally accepted models that have been used in periodic of knowledge progress that can be utilized in these assessments, which can be modified for qualitative assessments (Hernandez et al., 2018; Carlough \& McCall 2005).

The present qualitative study is one of the first to report on the assessment of knowledge gaps of TBAs working in indigenous areas of Guatemala and stresses the importance of enhancing their knowledge while respecting the traditions and building strong collaborative relationships between TBAs, nonprofit organizations, and MSPAS.

In addition to respecting cultural customs and traditions, there is a need to build strong collaborative relationships between international and national partners. Addressing the disparities of transportation at local, state, and national levels will help women at risk of complications to seek care earlier. These include future programs of construction of roads, bridges, and availability of vehicles in addition to funding programs to educate TBAs. 


\section{References}

Alkema,L.;Chou,D.;Hogan,D.;Zhang,S.;Moller,A.B.;Gemmill,A.;Fat,D.M.;Boerma,T.;Temmerman,M.; Mathers, C.; et al. Global, regional, and national levels and trends in maternal mortality between 1990 and 2015, with scenario-based projections to 2030: A systematic analysis by the UN Maternal Mortality Estimation InterAgency Group. Lancet 2016, 387, 462-474.

Ayiasi, R. M., Criel, B., Orach, C. G., Nabiwemba, E., \& Kolsteren, P. (2014). Primary healthcare worker knowledge related to prenatal and immediate newborn care: a cross sectional study in Masindi, Uganda. BMC health services research, 14, 65. https://doi.org/10.1186/1472-6963-14-65

Byrne, A., \& Morgan, A. (2011). How the integration of traditional birth attendants with formal health systems can increase skilled birth attendance. International journal of gynaecology and obstetrics: the official organ of the International Federation of Gynaecology and Obstetrics, 115(2), 127-134. https://doi.org/10.1016/j.ijgo.2011.06.019

Carlough, M., \& McCall, M. (2005). Skilled birth attendance: what does it mean and how can it be measured? A clinical skills assessment of maternal and child health workers in Nepal. International journal of gynaecology and obstetrics: the official organ of the International Federation of Gynaecology and Obstetrics, 89(2), 200-208. https://doi.org/10.1016/j.ijgo.2004.12.044

Chary, A., Díaz, A. K., Henderson, B., \& Rohloff, P. (2013). The changing role of indigenous lay midwives in Guatemala: new frameworks for analysis. Midwifery, 29(8), 852-858. https://doi.org/10.1016/j.midw.2012.08.011

Darmstadt GL, Lee AC, Cousens S, Sibley L, Bhutta ZA, Donnay F, et al. 60 million non-facility births: who can deliver in community settings to reduce intrapartum-related deaths? Int J Gynaecol Obstet 2009;107(suppl 1):S89112.

Fortney JA, Smith JB. Training of traditional birth attendants: issues and controversies. Durham, NC: Family Health International and United Nations Children's Fund, 1997.

Garcia, K., Dowling, D., \& Mettler, G. (2018). Teaching Guatemalan traditional birth attendants about obstetrical emergencies. Midwifery, 61, 36-38. https://doi.org/10.1016/j.midw.2018.02.012

Gill, C. J., Phiri-Mazala, G., Guerina, N. G., Kasimba, J., Mulenga, C., MacLeod, W. B., Waitolo, N., Knapp, A. B., Mirochnick, M., Mazimba, A., Fox, M. P., Sabin, L., Seidenberg, P., Simon, J. L., \& Hamer, D. H. (2011). Effect of training traditional birth attendants on neonatal mortality (Lufwanyama Neonatal Survival Project): randomised controlled study. BMJ (Clinical research ed.), 342, d346. https://doi.org/10.1136/bmj.d346.

Hernandez, S., Oliveira, J., Jones, L., Chumil, J., \& Shirazian, T. (2018). Impact of Standardized Prenatal Clinical Training for Traditional Birth Attendants in Rural Guatemala. Healthcare (Basel, Switzerland), 6(2), 60. https://doi.org/10.3390/healthcare6020060

Hernandez S, Oliveira JB, Shirazian T. How a Training Program Is Transforming the Role of Traditional Birth Attendants from Cultural Practitioners to Unique Health-care Providers: A Community Case Study in Rural Guatemala. Front Public Health. 2017;5:111. Published 2017 May 19. doi:10.3389/fpubh.2017.00111

Hussein, A. \& Mpembeni, R. (2005). Recognition of high risk pregnancies and referral practices among traditional birth attendants in Mkuranga District, Coast Region, Tanzania. African journal of reproductive health, 9(1), 113122.

Jokhio, A. H., Winter, H. R., \& Cheng, K. K. (2005). An intervention involving traditional birth attendants and perinatal and maternal mortality in Pakistan. The New England journal of medicine, 352(20), 2091-2099. https://doi.org/10.1056/NEJMsa042830

Ministerio de Salud Publica y Asistencia Social. EncuestaNacional de SaludMaterno Infantil: Informe Interno Priliminario; Ministerio de Salud Publica y Asistencia Social: Guatemala City, Guatemala, 2017.

MSPAS. Estudio Nacional de Mortalidad Materna 2011. Guatemala City. 2011. Available online: http://www.mspas.gob.gt/index.php/component/jdownloads/send/94-muerte-materna/805estudio-nacional-demortalidad-materna-2011

Walsh L. V. (2006). Beliefs and rituals in traditional birth attendant practice in Guatemala. Journal of transcultural nursing : official journal of the Transcultural Nursing Society, 17(2), 148-154. https://doi.org/10.1177/1043659605285412

Wilson, A., Gallos, I. D., Plana, N., Lissauer, D., Khan, K. S., Zamora, J., MacArthur, C., \& Coomarasamy, A. (2011). Effectiveness of strategies incorporating training and support of traditional birth attendants on perinatal 
Proceedings of the Global Public Health Conference, Vol.3, Issue 1, 2020, pp. 1-5

and maternal mortality: meta-analysis. BMJ (Clinical research ed.), 343, d7102. https://doi.org/10.1136/bmj.d7102

World Health Organization. Trends in maternal mortality: 1990 to 2008 estimates developed by WHO, UNICEF, UNFPA and The World Bank. 2010. World Health Organization, 2010.

World Health Organization. Millennium development goals report: 2007. United Nations Department of Economical and Social Affairs. United Nations, 2007

Zureick-Brown, S., Newby, H., Chou, D., Mizoguchi, N., Say, L., Suzuki, E., \& Wilmoth, J. (2013). Understanding global trends in maternal mortality. International perspectives on sexual and reproductive health, 39(1), 32-41. https://doi.org/10.1363/3903213 